\title{
J(৫)
}

Received: 26.05 .2020

Accepted: 01.06 .2020

Published: 14.06 .2020

JOTS, 4/2, 2020: 511-530

\section{Eski Uygurca Asgançu ve Asgançula-'nın Kökeni Üzerine}

\section{About the Etymology of Asyanču and Asyančula- in Old Uyghur}

\author{
Erdem UçAR \\ Friedrich-Schiller-Universität Jena (Jena/Germany) \\ E-mail: erdem.ucar@uni-jena.de
}

Researching the etymology of Old Turkic words has been one of the challenging fields of philology, since Turkish has spread to different geographic areas and has been in contact with different languages throughout its long history. It is also not easy to analyze the Old Turkic words diachronically. In order to overcome this difficulty, it need to make use of the branches of Turkish that are spread over different areas. The comparative Turkic languages method is the name of the method to be used to overcome this difficulty. It is much more difficult to find the origin of Old Turkic words than to find the origin of words in other periods of Turkish language. One of the words with ambiguous about its etymology is asyanču and asyančula-. In the article, the previous explanation about the etymology of the word was evaluated and a new proposal was proposed.

Key Words: etymology, asүanču, asyančula-, Old Uyghur. 
Eski Türkçe asgançu ve asgançula-'nın Eski Türk filolojisinde ilk kez fark edilmesi 112 yıl önceye rastlar. 112 yıllık zaman diliminde kelimenin okunuşu, kökeni ve anlamlandırılması yönünde farklı görüşler ortaya konmuştur. Aşağıdaki tabloda bu farklı görüşlerin listesini kronolojik sırada görmek mümkündür:

\begin{tabular}{|c|c|c|}
\hline Neşir veya Kaynak & asgançu & asgançula- \\
\hline Müller 1908: 9 & & osgançula- 'küçümsemek, aşağıllamak' \\
\hline Müller 1911: 76, 85 & & aş̧gançula- aşqançula- 'yükselmek' \\
\hline Bang 1926: 49, dip. 1 & & asgançula- 'birini aptal yerine koymak' \\
\hline $\begin{array}{c}\text { Bang-Gabain 1930a: 438; } \\
\text { 1930b: 196-197 }\end{array}$ & & asgançula- 'alay etmek' \\
\hline Bang 1931: 18, 20 & & $\begin{array}{l}\text { asgançula- 'iltifat etmek, gönlünü } \\
\text { almak' }\end{array}$ \\
\hline Rachmeti 1932: 402 & & asgançula- 'alay etmek' \\
\hline Arat 1942: 59 & & "asgançula- 'yüze gülmek' \\
\hline Clauson 1972: 284b-285a & $\begin{array}{c}\text { azgançu } \\
\text { 'aldatma, dalkavukluk' }\end{array}$ & azgançula- 'aldatmak' \\
\hline Tekin 1980: 187, 252 & "sq'nçw 'iltifat' & $\begin{array}{c}\text { "sq'nçwla'- 'iltifat etmek, gönlünü } \\
\text { almak' }\end{array}$ \\
\hline Zieme 1985: 97 & & asgançula- 'aldatmak' \\
\hline $\begin{array}{c}\text { Maue-Röhrborn 1984: } \\
\text { 308, 311; 1985: } 71 \\
\end{array}$ & & $\begin{array}{l}\text { asqançula- 'alay etmek, aldatmak, } \\
\text { kandırmak' }\end{array}$ \\
\hline $\begin{array}{l}\text { Röhrborn 1988: 233b- } \\
234 \mathrm{~b}\end{array}$ & $\begin{array}{c}\text { asqançu 'alay, alaylı } \\
\text { konuşma' }\end{array}$ & asqançula- 'alay etmek' \\
\hline Erdal 1991: 431 & & $\begin{array}{c}\text { asKançula- 'alay etmek, pohpohlamak, } \\
\text { dalkavukluk etmek, yapmacık bir } \\
\text { şekilde övmek' }\end{array}$ \\
\hline Kaya 1994: 121,154 & & asqançula- 'alay etmek' \\
\hline Geng et al. 1998: 64 & $\begin{array}{c}\text { asqançu 'alay, alaylı } \\
\text { konuşma' }\end{array}$ & \\
\hline Barat 2000: 122 & & azgançula- 'alay etmek' \\
\hline Röhrborn 2010: 89-90 & & $\begin{array}{l}\text { asqançula- '1. alay etmek, (bir kişiyi) } \\
\text { gülünç duruma düşürmek; 2. (birine) }\end{array}$ \\
\hline
\end{tabular}

1 Orijinal metindeki AWSXANÇWLA- yazımında muhtemelen hata vardır (Bang 1926: 49, dip. 1), kelime asgançula- olmalıdır, ancak MÜLLER'in kelimeyi 'küçümsemek, aşağılamak' ile anlamlandırması dikkate değer. 


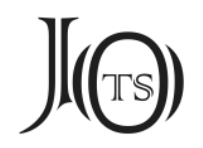

\begin{tabular}{|c|c|c|}
\hline & & $\begin{array}{c}\text { oyun oynamak, (birini) yalan } \\
\text { söyleyerek kandırmak' }\end{array}$ \\
\hline Röhrborn 2015a: 302-303 & $\begin{array}{c}\text { asqançu 'alay, alaylı } \\
\text { konuşma (Budizmde } 10 \\
\text { ana günahtan biri, } \\
\text { Skr. saṃbhinnapralāpa)' }\end{array}$ & \\
\hline Nasilov et al. 2016: $64 b^{2}$ & & $\begin{array}{l}\text { asgançula- 'pohpohlamak, dalkavukluk } \\
\text { etmek, yapmacık bir şekilde övmek' }\end{array}$ \\
\hline $\begin{array}{c}\text { Wilkens 2016: 626, 628, } \\
\text { vd. }\end{array}$ & $\begin{array}{l}\text { asqançu 'alay, alaylı } \\
\text { konuşma' }\end{array}$ & asqançula- 'alay etmek' \\
\hline Özertural 2020: 16 & & asqançula- 'alay etmek, eğlenmek' \\
\hline
\end{tabular}

Yukarıdaki tabloda görüldüğü üzere kelimenin şimdiye kadar osgançu, aşgançu, azgançu, asqançu ve asgançu şekillerinde birbirinden farklı olarak okunduğu görülüyor. Kelimeye verilen anlamların ise MÜLLER'inkini bir kenarda bırakırsak, önemli ölçüde birbirini tuttuğu söylenebilir. Okuyuş farklılıklarının nedeni şüphesiz kelimenin kökeninin net olarak açıklığa kavuşturulmamış olmasıdır. Eğer kelimenin kökeni belirlenebilirse okunuşu konusundaki tereddütler de kendiliğinden ortadan kalkacaktır.

Görebildiğim kadarıyla asgançu hakkında ilk açılamayı yapan BANG olmuştur. BANG, Müller 1908'deki osgançula- okunuşunun orijinal metindeki yazım hatasından kaynaklandığını söylerek okunuşu asgançula- ile düzeltmiştir. Kelimenin kökünü tanıklanmamış *asga- veya *asgan-'a a , bunları da *asıg+a-n-'a (asıg 'fayda') bağlamış ve iç ses düşmesiyle *asga-ve *asgan-'in meydana geldiğini ifade etmiştir. Ona göre, asıl kök as- olmalıdır ve bu as- muhtemelen RADLOFF'un sözlüğündeki (1893/I: 530) as- (I) 'bir şeyin üzerinden aşmak' fiilidir. Ayrıca, Şorcadaki askay 'alay' kelimesini de bu as-'a bağlayarak kelimenin analizini şöyle yapmıştır: askay < *asgay < *asga-y-a (1926: 49, dip. 1). BANG'ın kelimenin kökenini Türkçe içinde araması dikkat çekicidir.

2 Nasilov et al. 2016, Uluslararası Türk Akademisi (TWESCO) tarafından neşredilen Nadelyayev et al. 1969'un ikinci baskısıdır. Sözlüğün ikinci baskısında hazırlayanların adı dışında değişen pek fazla bir şey gözükmemektedir. İlk baskıda hazırlayan üç kişinin adı bu baskıda çıkartılmıştır.

3 BANG, kuvvetlendirme işlevli \{-gA-\} hakkındaki izahına da bakılmasını söylemiştir, zira ona göre bu kelimede $\{-g A-\}$ eki bulunmaktadır. İzahı için bk. 1925: 397-401. 


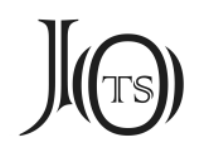

Daha sonra, BANG ve GABAIN, asgançula-'nın 'alay etmek, yalandan iltifat etmek' gibi anlamları olduğunu söyleyip asgançula- ile benzer anlamda kullanılan togunla-'ya dikkati çekmiş ve asgançula-'nın Budizmdeki 10 günah arasında sıralandığını ifade etmiştir (1930a: 448).

Drevnetyurkskiy Slovar'da asgançu bulunmaz, sadece asgançula- vardır ve fiilin tagunla- (sic!) ile kullanıldığında 'dalkavukluk yapmak' anlamına geldiği ifade edilmiştir (Nadelyayev et al. 1969: 60a; Nasilov et al. 2016: 64b).

CLAUSON, kelimenin isim şeklinin kesinlikle azgançu 'aldatmak, dalkavukluk' şeklinde okunması gerektiğini ve bunun da $a z$ - 'sapmak' fiiline dayandığını söylemiş, kelimenin fiil şeklini de azgançula- 'aldatmak' olarak göstermiştir (1972: 284b-285a).

BAILEY, İranî bir dil olan Sakaca (Hotan) khan- 'gülmek' (Farsça xand-, xandìdan) fiilinden bahsederken Eski Uygurcadaki osgançula-'nın (sic!) (Müller 1908: 9'daki) Soğdça us-xand- kaynaklı olabileceğini iddia etmiştir (1979: 71a-b).

MAUE ve RöHRBORN, Tibet harfli metinde 'A-SKAN-CU-LA-MA-SA şeklinde geçen kelimeyi asqançula- olarak okuyup fiilin 'birine gülmek, birisiyle alay etmek, eğlenmek' anlamına dikkat çeker. Xuanzang Biyografisi'nde kül- asqançulaikilemesinin Çince metinde 虽笑 chixiao 'alaylı gülmek' (Giles 1964: 1951 4343) karşıllı̆̆ında olduğu söylenmiştir. Bununla beraber, asqançu ile aynı anlama gelen TAXWN tagon kelimesinin de Çince 他言 tayan (Giles 1964: 10494 13025) kökenli olabileceğine ihtimal verilmiştir (1985: 71, dip. 131).

RÖHRBORN, Uigurisches Wörterbuch'un eski versiyonunda kelimeleri asqançu 'alaylı konuşma' ve asqançula- '1. alay etmek; 2. aldatmak, birini yalan söylerek kandırmak' şeklinde okuyup anlamlandırmıştır. Kelimenin kökeniyle ilgili olarak BANG (1926), CLAUSON (1972) ve BAILEY'in (1979) tespitlerine yer vermiş, bunlardan BANG ve CLAUSON'un köken tekliflerinin anlamsal bakımdan kabul edilemeyeceğini, BAILEY'inkinin ise anlam bakımından uygun olduğunu, ama kelime yapımı açısından onun teklifinin izaha muhtaç olduğunu ifade etmiştir. Ayrıca, BANG'in ileri sürdüğü Şorca askay'ın kelime ile ilişkisine ihtimal vermiştir (1988: 233b-234b). 


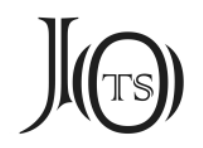

ERDAL, asKançula-'nın (sic!) ikinci hecesindeki ünsüzün sedalı veya sedasız olup olmadığı konusunda emin değildir. Fiili 'birisiyle eğlenmek, alay etmek' anlaminda göstermiștir. Ayrıca, MAUE ve RöHRBORN'un Tibet harfli metinde fiili askançula- şeklinde okuma önerisinde metnin yeterli kanıt sunmadığını söylemiştir (1991: 431).

Uigurisches Wörterbuch'un yeni versiyonundaki asqançu maddesinde kelime İranî kökenli olarak gösterilmiştir. asqançula-'nın yapısı oldukça açıktır. İsim tabanı asqançu'nun üzerine $\{+1 \mathrm{~A}-\}$ eki getirilerek asqançula- '1. alay etmek, bir kişiyi gülünç duruma düşürmek; 2. birine oyun oynamak, birini yalan söyleyerek kandırmak' teşkil edilmiştir. asqançu'nun kökeni için ise, kelimenin muhtemelen Soğdça sx'nt 'alay etmek' (Sims-Williams \& Durkin-Meisterernst 2012: 180a) veya Partça 'sxnd 'alay etmek' (Durkin-Meisterernst 2004: 91b) kaynaklı olabilieceği, ancak morfolojik ayrıntıların henüz netleştirilemediği söylenmiştir. Sözlükte, BANG ve CLAUSON'un ileri sürdüğü Türkçe köken tekliflerinin anlamsal açıdan sorunlu olduğu belirtilmiş ve asqançu için 'alay, alaylı konuşma, Budizmde 10 ana günahtan biri, Sanskritçe saṃbhinnapralāpa' anlamı kaydedilmiştir (Röhrborn 2010: 89-90; 2015a: 302-303).

Yukarıdaki köken tekliflerine bakılınca, BANG ve CLAUSON'un önerilerinin anlamsal bakımdan kelimenin kökenini açıklamadan uzak olduğu görülmektedir. Diğer taraftan, anlamsal açıdan uygun gözüken BAILEY ve RÖHRBORN'un teklifleri ise kelimeyi seslik ve yapısal bakımdan açıklamamaktadır. Bu nedenle kelimenin kökeni konusunda farklı bir önerinin ortaya konması mümkün gözükmektedir.

Kelimelerin okunuşunu ve kökenini tespit etmek için Eski Uygurca metinlerde AASXANÇW ve AASXANÇWLA-'nın geçtiği yerleri listelemek faydalı olacaktir:

\begin{tabular}{||c||l||l||}
\hline \multicolumn{2}{|c||}{ AASXANÇW AAS ẌANÇW } \\
\hline \hline 1 & AASXANÇW t(a)gon sav sözledim(i)z (Maitrisimit, 177 r7-8) & Tekin 1980: 187 \\
\hline \hline 2 & ad(1)nagu AASẌANÇW bolur (Mainz 675 v6) & Kasai 2011: 146 \\
\hline \hline 3 & $\begin{array}{l}\text { AASXANÇW tagon sav sözlemek (Maitrisimit'in Hami yazmas1, 26. } \\
\text { Bölüm, 6 v16-17) }\end{array}$ & Geng et al. 1998: 64 \\
\hline \hline 4 & $\begin{array}{l}\text { bir ag1z tagon [asgançu söz]l[ed]ükde tegirmileyü körür (DKPAM, } \\
\text { U 1183+Mainz 233+Mainz 864b+U 1084+U 1202 v1-2) }\end{array}$ & Wilkens 2016/I: 620-621 \\
\hline
\end{tabular}




\begin{tabular}{|c|c|c|}
\hline 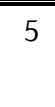 & $\begin{array}{l}\text { bu tagon AASXANÇW savlarıg ... munta ol qalıp (DKPAM, U } \\
1324+\mathrm{Kr} \text { II 1/31+U 1085+Mainz 63+U 1056+U } 1191 \text { v25-26) }\end{array}$ & Wilkens 2016/I: 620-621 \\
\hline 6 & tagon AASXANÇW sav sözleyürler (DKPAM, Mainz 751 r9-10) & Wilkens 2016/I: 626-627 \\
\hline 7 & $\begin{array}{l}\text { negülük tagon AASXANÇW sav sözleyür m(e)n tép (DKPAM, Mainz } \\
661 \text { r11-12) }\end{array}$ & Wilkens 2016/I: 650-651 \\
\hline 8 & $\begin{array}{l}\text { kim kayu tagon AASXANÇW sav üküş sözleser (DKPAM, Mainz } 751 \\
\text { r18-19) }\end{array}$ & Wilkens 2016/I: 626-627 \\
\hline 9 & $\begin{array}{l}\text { tagon AASXANÇW sözlemekte üküş ögretig q1lmış [bolurlar] } \\
\text { (DKPAM, Mainz } 661 \text { r14-15) }\end{array}$ & Wilkens 2016/I: 650-651 \\
\hline 10 & kim qayu kişi tagon AASXANÇW sözlegeli (DKPAM, Mainz 661 r5) & Wilkens 2016/I: 650-651 \\
\hline 11 & $\begin{array}{l}\text { anı üçün öglüg köyüllüg kişi tagon AASXANÇW sözlemektin } \\
\text { etözin yıgınıp (DKPAM, Mainz } 661 \text { v6-8) }\end{array}$ & Wilkens 2016/I: 652-653 \\
\hline 12 & $\begin{array}{l}\text { yme tagon AASXANÇW sözlemeknin münin qadagın bilmetin } \\
\text { (DKPAM, Mainz } 661 \mathrm{r} 23-24 \text { ) }\end{array}$ & Wilkens 2016/I: 652-653 \\
\hline 13 & $\begin{array}{l}\text { [tag]on AASXANÇW sav sözlemek[ig yérme]k atl(1)g yétinç bölök } \\
\text { (DKPAM, U } 2076 \text { v11-12) }\end{array}$ & Wilkens 2016/I: 654-655 \\
\hline 14 & $\begin{array}{l}\text { tagon AASXANÇW savqa etözümin küzedgeli umatın turur m(e)n } \\
\text { (DKPAM, Mainz } 661 \text { v33-35) }\end{array}$ & Wilkens 2016/I: 654-655 \\
\hline \multicolumn{3}{|c|}{ AASXANÇWLA- AASX்ANÇWLA- AASẌXNÇWLA- } \\
\hline 1 & mini AWSXANÇWLADY bo mogoçlar (*U 9175 r71) & $\begin{array}{l}\text { Müller 1908: 9; Zieme } \\
\text { 2015: 49-55 }\end{array}$ \\
\hline 2 & $\begin{array}{l}\text { eyrig sarsıg sav sözledim erser AASXWNÇWLADYM erser köyülin } \\
\text { adın k(i)şinin edgüsine köni saqınç turgurdum erser (*U } 9090 \text { r6- } \\
\text { 8) }\end{array}$ & Müller 1911: 76 \\
\hline 3 & $\begin{array}{l}\text { eyrig sarsıg sav sözledim erser AASẌANÇWLADYM könülin } \\
\text { ad(1)nagunuy edgüsine köni saqınç turgurmatım erser (*U } 9091 \\
\text { r23-25) }\end{array}$ & Müller 1911: 85 \\
\hline 4 & $\begin{array}{l}\text { eyrig sarsıg sav sözledimiz erser } \text { AASXANÇWLADYMZ } \\
\text { tagonladımız erser (Mainz 734 II r71-72) }\end{array}$ & Bang-Gabain 1930a: 438 \\
\hline 5 & $\begin{array}{l}\text { kim qayu okısar AASXANÇWLAMASWN érmezün }{ }^{4} \text { (U 560: 13a r2- } \\
\text { 3) }\end{array}$ & Rachmeti 1932: 402 \\
\hline
\end{tabular}

4 RACHMETİ, ayamasun 'in Ehren Halten' (Rachmeti 1932: 402, dip. 1), RöHRBORN ise érmezün 'kritisieren' (2010: 90) şeklinde okuyup anlamlandırmıştır. İki okuma da kesin değildir, zira orijinal metinde kelimenin ilk harfi net olarak gözükmemektedir. Ama RöHRBORN'un okuyuşu metnin bağlamı açısından biraz daha uygun gibidir. Eski Türkçe ir- ér- yér- 'üzmek, rahatsız etmek, can sıkmak' (Clauson 1972: 194a-b; Erdal 1991: 366, 599-600; Özertural 20020: 23-26) fiili bugün Anadolu ağılarında hâlâ yaşamaktadır. Krş. ır- 'üzmek, eziyet vermek' (DS: 2488a). 


\begin{tabular}{|c|c|c|}
\hline 6 & $\begin{array}{l}\text { özümte yavızlarıg körüp uçuzlatım AASXANÇWLATYM erser (AY } \\
\text { 136/13-14) }\end{array}$ & $\begin{array}{l}\text { Bang-Gabain 1930b: 196- } \\
\text { 197; Kaya 1994: } 121\end{array}$ \\
\hline 7 & ötrü ol kam AASXANÇWLAYW inçe tép aydı (U 36 v12+U 205e) & Bang 1931: 18 \\
\hline 8 & $\begin{array}{l}\text { ötrü ol qam AASXANÇWLAYW üç yolı inçe tép tédi (U } 36 \text { v13+U } \\
\text { 205e) }\end{array}$ & Bang 1931: 18 \\
\hline 9 & ezügin tınlıglarıg AASXANÇWLAYWR erdi (Maitrisimit, 202 r9-10) & Tekin 1980: 252 \\
\hline 10 & $\begin{array}{l}\text { olar bizni külgülük AASX்ANÇWLAX்WLWẌ bulgay tép (Xuanzang } \\
\text { Biyografisi IX, HtPek 96b 8) }\end{array}$ & Barat 2000: 122 \\
\hline 11 & $\begin{array}{l}\text { eyrig sarsig sav sözlememek AASXANÇWLAMAMAX erser (AY } \\
220 / 2-3 \text { ) }\end{array}$ & Kaya 1994: 154 \\
\hline 12 & $\begin{array}{l}\text { t(e)vlig kürlüg saqınçın atasın AASXANÇWLAYW inçe tép tédi } \\
\text { (Mainz } 826 \text { r14-16) }\end{array}$ & - \\
\hline 13 & [ö]trü yene AASXANÇWLAY[W] (Mainz 470 r1) & - \\
\hline 14 & öyilerke künileyü AASẌANÇWLAMÄ̈ (U 6656b r1) & Zieme 1985: 97 \\
\hline 15 & $\begin{array}{l}\text { AASXANÇWLAY[W sözlegüçi kiş]inin tegresin[te üküş kişi } \\
\text { y1]g1lsar anıy [inçe tép saqınçı bolu]r (DKPAM, U 1183+Mainz } \\
\text { 233+Mainz 864b+U 1084+U } 1202 \text { v15-18) }\end{array}$ & Wilkens 2016/I: 620-621 \\
\hline 16 & $\begin{array}{l}\text { ançada berü AASXANÇWLAYW s[özlemiş] (DKPAM, U 1183+Mainz } \\
\text { 233+Mainz 864b+U 1084+U } 1202 \text { v23) }\end{array}$ & Wilkens 2016/I: 620-621 \\
\hline 17 & $\begin{array}{l}\text { kim birök tagon savag sevip taplap tou quvrag arasınta üküş } \\
\text { tınl(1)glarıg AASXANÇWLASAR (DKPAM, Mainz } 751 \text { r10-12) }\end{array}$ & Wilkens 2016/I: 626-627 \\
\hline 18 & $\begin{array}{l}\text { erüş üküş tınl(1)glar tagon AASXANÇWLAYW sözlemektin } \\
\text { tıdılgaylar (DKPAM, Mainz } 751 \text { v2-3) }\end{array}$ & Wilkens 2016/I: 628-629 \\
\hline 19 & $\begin{array}{l}\text { anı odguraq AASẌANÇWLAYWR inçip ogulum yavaz üd kelyük ol } \\
\text { (DKPAM, U 1039+Mainz 64a+U1608+U 981d v5-6) }\end{array}$ & Wilkens 2016/I: 300-301 \\
\hline 20 & $\begin{array}{l}\text { nizvanilarnıy AASXANÇWLAMAẌYN serü umadın (DKPAM, Kr II } \\
\text { 1/2 v22-23) }\end{array}$ & "Wilkens 2016/I: 508-509 \\
\hline 21 & $\begin{array}{l}\text { adınlarıg AASXANÇWLAYW sözlemiş savları ol ugurda ne erser } \\
\text { tusulmaz (DKPAM, Mainz } 661 \text { r27-28) }\end{array}$ & Wilkens 2016/I: 652-653 \\
\hline 22 & $\begin{array}{l}\text { tınl(1)gla[rqa] uçuz bolup élüglegülük AASXANÇWLAXWLWX } \\
\text { [bolurla]r (DKPAM, Mainz } 661 \text { r34-35) }\end{array}$ & Wilkens 2016/I: 652-653 \\
\hline 23 & $\begin{array}{l}\text { adınlarıg AASXANÇWLAYW élügleyü sözlemiş tıltagınta (DKPAM, } \\
\text { Mainz } 661 \text { v26-27) }\end{array}$ & Wilkens 2016/I: 654-655 \\
\hline
\end{tabular}

Yukarıdaki tabloda görüldüğü üzere asgançu ve asgançula-'nın bazı kelimelerle birlikte kullanımı dikkati çekmektedir. Beraber kullanıldığı kelimeleri de listelemek faydalı olabilir: 


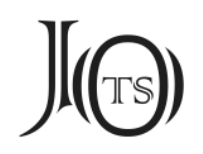

\section{asgançu tagon $\sim$ tagon asgançu ve asgançula- tagonla-}

CLAUson, tagon ve türemişlerini şöyle kaydetmiştir: tagun (sic!) 'yağcllık, dalkavukluk' (1972: 470b), tagunçı 'sırdaş' (1972: 471a), tagunla- 'dalkavukluk yaparak aldatmak' (1972: 471a). O, tagunçı ile tagunla-'yı tekörnek (hapax legomenon) olarak kaydetmiştir, ama son çıkan DKPAM neşrinde tagonçı ile tagonla-'nın tekörnek olmadığı anlaşılmıştır. Bk. Wilkens 2016/III: 1057a. MAUE ve RöHRBORN, tagon tagun'un kaynağının Çince 他言 tayan (Giles 1964: 10494 13025) olduğunu ileri sürmüştür (1985: 71, dip. 131). CLAUSON, Anadolu ağızlarındaki dağna- 'küçümsemek, kınamak' ile tagun arasında ilişki olabileceğinden şüphelenmiştir (1972: 470b). Gerçekten de Anadolu ağızlarında tagon ile ilişkili bazı kelimelere rastlanıyor: danla- dagna- dajla- '1. şaşmak; 2. kınamak' (DS: 1362a-b); dayna- dayla- danla- '1. birisini över ya da kınarken abartarak konuşmak; 2. azarlamak, kızmak' (DS: 1363a); dansa- 'alay etmek, beğenmemek' (DS: 1363b); dansak 'gururlu, kibirli, alayc1, münasebetsiz kimse' (DS: 1363b). TIETZE, danl danl 'kinayeli konuşmak', danla- 'birisini över ya da kınarken çok abartarak konuşmak'; dansa- 'beğenmemek, ayıplamak, alay etmek' (2016: 306307) kelimelerinin dan/tan (II) 'yalan' sözüne dayandığını söylemiş, ama sözlüğündeki dan/tan (II) 'şaşma, şaşılacak şey’ maddesinde kelimenin Eski Türkçe tạ’a dayandığını ifade etmiştir (2016/II: 301). TIETZE’nin bahsettiği tạ (II) kelimesi Eski Türkçede 'şaşırma, süpriz' anlamındadır (Clauson 1972: 510b-511a), kelimenin 'yalan' anlamına rastlanmaz. Dolayısıyla TIETZE’nin önerdiği denkliğin doğru olmadığı açıktır. Bence Eski Uygurcadaki tagon tagun kelimesi, Anadolu'ya şu aşamalardan geçerek ulaşmış olmalıdır: tagon tagun > *dagun > *daun > dan. O hâlde, yukarıda zikredilen Anadolu ağızlarındaki kelimelerin analizi şöyle yapilabilir: danla- $<$ dan+la-, dansa- $<$ dan+sa-, danlı $<$ danlı. Bununla beraber, Anadolu ağızlarındaki danla- dagna- dạla- fiilinin iki farklı kaynağ olmalıdır, yani 'şaşmak' anlamındaki fiilin kaynağı Eski Türkçe tạ'a dayanırken, 'azarlamak, kızmak, kınamak' anlamındaki fiil Eski Türkçe tagon tagun ile ilgili olmalıdır. Bugün Türkiye Türkçesinde sıkça kullanılan qafaya dang etmek'teki dang muhtemelen Eski Türkçe tạ ‘şaşırma' ile ilgilidir. 


\section{$J(\Theta)$}

\section{uçuzla- asgançula-}

Eski Türkçede uçuzla- (< uçuz+la-) fiili 'hakir görmek, küşük düşürmek, kıymetini düşürmek' (Clauson 1972: 32b; Erdal 1991: 449) anlamına gelmektedir.

\section{asgançula- ér-}

Eski Türkçede ér- yér- 'ayıplamak, kınamak' (Özertural 2020: 24) fiili ile beraber asgançula- kullanılmıştır.

\section{asgançula- élügle-}

Eski Türkçede élügle- ilügle- (< ilüg+le-) 'alay etmek, dalga geçmek' (Clauson 1972: 142a, 145a; Özertural 2020: 15-16) anlamındadır. Buradaki élügle(< *élüg+le-) fiili asgançula- ile aynı anlama gelmektedir, ancak élügle-'nin kökü olan *élüg 'şaka' şimdiye değin Eski Türkçede tanıklanmamıştır.

\section{eyrig sarsıg sav sözle- asgançula-}

Eski Türkçede eyrig sarsıg ' $\mathrm{kaba}_{2}$ ' ikileme olarak kullanılmıştır (Erdal 1991: 200-201, dip. 241). Tibet harfli metindeki 'YHI-RIG yazımına (Maue-Röhrborn 1984: 308) bakılarak Erdal 1991 ve Uigurisches Wörterbuch'ta eyrig okunuşu kabul edilmiştir. CLAUSON, kelimeyi irig olarak okur (1972: 222a-b). Eğer onun söylediği gibi Eski Türkçe kelimenin Anadolu sahasında iri şeklinde yaşadığı kabul edilecek olunursa, Tibet harfli metindeki tanığa rağmen kelimenin eyrig şeklinde okunuşunun şüpheli olduğu söylenebilir. Uygur ve Arap harfli metinlerde kelimenin ilk hecesi AY şeklinde yazıldığından kelimenin eyrig veya irig olarak okunuşunda tereddüte düşülmüştür. Daha geniş bilgi için bk. Röhrborn 2015b: 471-476.

\section{kül- asgançula-}

Eski Türkçede kül- fiili bugün kullandığımız 'gülmek' anlamındadır (Clauson 1972: 715b-716a). CLAUSON, kül- maddesinde Eski Uygurcadan tanık getirmemiştir. Şimdiye değin asgançula- için 'alay etmek' anlamının verilişinde fiilin kül- ile birlikte kullanımı etkili olmuştur. 
Eski Uygurca metinlerde asgançu ve asgançula-'nın Budist çevreye ait metinlerde özel bir bağlamda kullanıldığı anlaşılıyor. Mahāyāna Budizminde on ahlakî davranıştan veya on günahtan bahsedilir. Eski Uygurcaya Tohar (A) dilinden tercüme edilen on bölümlük Daśakarmapathāvadānamālā'da (DKPAM) her bölüm bu on ahlakî davranıştan birini temsil etmektedir. Çin Budizminde 十 善業 shi shan ye ve Sanskritçe daśa-kuśala-karma-patha olarak bilinen bu on ahlakî davranışın, yani on törlüg qulınç yolları veya on törlüg k(a)rmaput'un üç tanesi etöz 'beden', dört tanesi til 'dil' ve üç tanesi de köyül 'zihin' vasıtasıyla gerçekleşir: etözin üç tilin tört törlüg könülteki qulınç yme üç törlüg bolar (AY 107/15-17 [Kaya 1994: 109]). On ahlakî davranışın Uygurcadaki terminolojisini çeşitli günah çıarma metinlerine ait şu parçalarda tespit etmek mümkündür: Mainz 734 I+II (T II Y 47) [Bang-Gabain 1930a: 438-439]; *U 9090 (T II Y 48) [Müller 1911: 76]; *U 9094 (T II Y 59d) [Bang-Gabain 1930a: 438-439]; Maitrisimit' in Hami yazmas1, 26. bölüm, 6v [Geng et al. 1998: 64]. Ayrica, Arat 1942: 59'da on maddenin tamamı anlamiyla beraber listelenmiştir. Eski Uygurca on törlüg kıllnç yolları veya on törlüg $k(a)$ rmaput şunlardır:

\begin{tabular}{|c|c|c|c|}
\hline No & Eski Uygurca & Türkiye Türkçesi & Çince ve Sanskritçe ${ }^{5}$ \\
\hline \multicolumn{4}{|c|}{ etöz 'beden' ile işlenenler } \\
\hline 1 & $\begin{array}{l}\text { özlüglerig ölürme-, ölüt ölürme-, } \\
\text { adınlarnıy ed tavar üzeki isig özin } \\
\text { üzüp kentü etözümin igid- }\end{array}$ & öldürmek & $\begin{array}{c}\text { 不殺生 bu sha sheng = } \\
\text { prānāāipātād vairaman̄ī } \\
\text { (Soothill-Hodous 1937: 107). }\end{array}$ \\
\hline 2 & $\begin{array}{c}\text { adınagunuy tavarın küçep alma-, } \\
\text { adınagunuy tavarın ogurla-, ogrı } \\
\text { ogurla- }\end{array}$ & hırsılik yapmak & $\begin{array}{c}\text { 不偷盜 bu tau dao = } \\
\text { adinnâdāna-veraman̄i } \\
\text { (Soothill-Hodous 1937: 104). }\end{array}$ \\
\hline 3 & $\begin{array}{l}\text { adınlarnıy yutuzına yapşınma-, evin } \\
\text { yutuzuna yazın-, adın amraqın amra- }\end{array}$ & $\begin{array}{l}\text { başkasının karısına } \\
\text { musallat olmak }\end{array}$ & $\begin{array}{c}\text { 不邪淫 bu xie yin = kāma- } \\
\text { mithyācārādviratị }\end{array}$ \\
\hline \multicolumn{4}{|c|}{ til 'dil' ile işlenenler } \\
\hline 4 & $\begin{array}{c}\text { ezügleme-, ezüg sav sözle-, tilin ezüg } \\
\text { yalgan sav sözle- }\end{array}$ & yalan söylemek & $\begin{array}{c}\text { 不妄語 bu wan gyu = } \\
\text { musāvādā-veraman̄ī } \\
\text { (Soothill-Hodous 1937: 106). }\end{array}$ \\
\hline 5 & $\begin{array}{c}\text { çaşut çaşurma-, çaşut sav sözle-, } \\
\text { çaşur- yoya-, çaşut yoyag kıl- }\end{array}$ & iftira atmak & $\begin{array}{l}\text { 不惡口 bu wu kou = paruṣa- } \\
\text { vacana-viramaṇa, paruṣa- }\end{array}$ \\
\hline
\end{tabular}

Sanskritçe ve Çince denkliklerde Soothill-Hodous 1937 dışında ayrıca (www.buddhism-dict.net) adresindeki maddelerden de yararlanılmıştır. 


\section{$J(\Theta)$}

\begin{tabular}{|c|c|c|c|}
\hline & & & $\begin{array}{c}\text { vacanād viramayati, } \\
\text { pāruṣyāt prativiratih } \\
\text { (Soothill-Hodous 1937: 372). }\end{array}$ \\
\hline 6 & $\begin{array}{c}\text { irig sarsig sav sözleme-, sarsig sav } \\
\text { sözle- }\end{array}$ & kaba konuşmak & $\begin{array}{c}\text { 不兩舌 bu liang she = piśuna- } \\
\text { vacana-viramaṇa, piśuna- } \\
\text { vacanād vivecayati, } \\
\text { paiśunyāt prativirati } \\
\text { (Soothill-Hodous 1937: 250). }\end{array}$ \\
\hline 7 & $\begin{array}{l}\text { asgançulama-, asgançu tagon sav } \\
\text { sözle- , asgançula- tagonla- }\end{array}$ & alay etmek & $\begin{array}{c}\text { 不綺語 bu ki yu = sambhinna- } \\
\text { pralāpāt prativirati, } \\
\text { sambhinna-prarāpa- } \\
\text { viramaṇa } \\
\text { (Soothill-Hodous 1937: 108). }\end{array}$ \\
\hline \multicolumn{4}{|c|}{ köyül 'zihin' ile işlenenler } \\
\hline 8 & $\begin{array}{c}\text { adın kişinin edgüsine azlanma-, } \\
\text { künileme-, köyülin adınagunuy } \\
\text { edgüsine küni saqıç turgur-, } \\
\text { az turgur- }\end{array}$ & açgözlü olmak & $\begin{array}{c}\text { 不貪欲 bu tan yu } \\
\text { (Soothill-Hodous 1937: 184). }\end{array}$ \\
\hline 9 & $\begin{array}{c}\text { övke köyül tutma-, övkelenme-, övke } \\
\text { öz } z^{6} \text { buz köyül tut-, övke turgur- }\end{array}$ & sinirlenmek & $\begin{array}{l}\text { 不瞋靑 bu zhen hui = } \\
\text { vyāpāda-viramaṇa. }\end{array}$ \\
\hline 10 & $\begin{array}{l}\text { ters körüm öritme-, } \\
\text { ters tetrü körüm turgur- }\end{array}$ & $\begin{array}{l}\text { yanlış düşüncelere } \\
\text { kapılmak }\end{array}$ & $\begin{array}{c}\text { 不邪見 bu xie jian = mithyā- } \\
\text { darśana-viramaṇa, mithyā- } \\
\text { darșțeh prativiratih. }\end{array}$ \\
\hline
\end{tabular}

Buna göre, asgançu 'alay' ve asgançula- 'alay etmek' Budizm'de on günah içinde 7. sırada, til 'dil' ile işlenen günahlar içinde ise 4. sırada yer almaktadır. Dolayısıyla asgançu'nın Budist çevrenin dinî terminolojisine ait bir kelime olduğu söylenebilir.

Eski Uygurca asgançu'nun kökeninin Türkçe içinde arabileceğini düşünüyor ve kelimenin kökeni için şöyle bir teklifte bulunmak istiyorum: *agız+a- > *agiz+a-nçu > *agzançu > *azgançu > asgançu. Bu gelişme esnasında, göçüşmenin etkisiyle teşekkül noktaları aynı olan ünsüzlerde değişim (/z/ > /s/) olmuş, yani sedalı ünsüz sedalılaşmıştır. Eski Türkçede $\{-(X) n c ̧ U\}$ eki (Erdal 1991: 285-290) asgançu gibi çeşitli kavramların üretimine uygun bir eke benzemektedir: ögrünçü ‘sevinç' (< ögir-ünçü), alkınçu ‘son' (< *alk1-nçu), vs.

6 Kelimenin kökeni için bk. Uçar 2017: 1-11. 


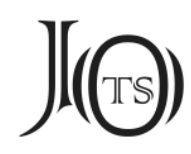

Aslında agız sözü anlamçevirisi yoluyla da olsa 'dedikodu, söylenti' (Röhrborn 2015a: 67) gibi negatif anlamda Eski Uygurcada kullanılmıştır. Ancak agız belki de böyle bir anlamı anlamçevirisiyle değil, Türkçenin kendi anlam dünyası içinde kazanmış olabilir. Bugün Türkiye Türkçesinde ağız sözünün çeşitli metaforik anlamları mevcuttur. Üstelik insan bedenindeki konuşma organlarından biri olan ağızın bu tür metaforik anlamlar kazanması da gayet doğaldır. Belki de asgançu'nun kökenindeki agız da böyle negatif bir anlama gelmekteydi. Anadolu ağızlarında, 'bir kimsenin sözlerini alaylı bir şekilde tekrarlamak' anlamına gelen ve ağız ile oluşturulan çeşitli birleşik yapılar

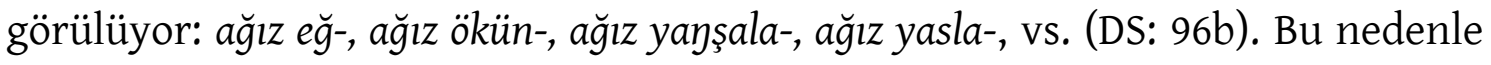
asgançu ve asgançula-'nın anlamı üzerinde de kısaca durmak istiyorum.

Çince Budist terimler içinde asgançula-'nın karşıllı̆ında 綺語 qi yu (Giles 1964: 998 13626) vardır. Çince karakterler, 'hoş konuşmak, süslü laflar etmek' veya 'müstehcen konuşmak' (Soothill-Hodous 1937: 427a) gibi anlamlara gelmektedir. Ancak, ifade olumsuz yapıda 不綺語 bu qiyu şeklinde kullanılınca 'yersiz, boş ve kırıcı konuşmak' (Soothill-Hodous 1937: 108b) anlamındadır. Ayrıca, Çin Budizminde bu günah 語四過 yu siguo terimiyle de ifade edilir ve dil ile yapılan dört kusurlu davranıştan biri kabul edilir. Bu dört yanlış davranış şunlardır: 1. yalan söylemek, 2. iftira atmak, 3. kaba konuşmak, 4. dalkavukluk yapmak (Hirakawa 1997: 1077b). Sonuç itibariyle, Çin Budizminde 綺語 qi yu karakterlerinin '1. ciddiyetsiz konuşmak, boş konuşmak; 2. kalp kırıcı sözler etmek; 3. dalkavukluk gayesiyle konuşmak' gibi negatif anlamları barındırdığı anlaşılmaktadır.

Uigurisches Wörterbuch'un yeni serisinde asgançu 'alay, alaylı konuşma, Budizm'de 10 ana günahtan biri, Skr. saṃbhinnapralāpa' (Röhrborn 2015: 303) ve asgançula- '1. alay etmek, bir kişiyi gülünç duruma düşürmek; 2. birine oyun oynamak, birini yalan söyleyerek kandırmak' (Röhrborn 2010: 90) ile anlamlandırılmıştı. Eski Uygurcada asgançula-'nın beraber kullanıldığı kelimelere bakıldığında fiilin ilk anlamının 'alay etmek' olduğunu söylemek güçtür. Fiilin beraber kullanıldığı yapılar şunlardır: uçuzla- asgançula-, asgançula-ér-, asgançula-élügle-, eyrig sarsıg sav sözle- asgançula-, künile- asgançula-, kül- asgançula-. Bunlardan sadece külkısmen fiilin 'alay etmek' anlamında olabileceğini düşündürmektedir. 


\section{J(৫)}

Bundan ötürü, bence fiilin üç anlamının olduğu tahmin edilebilir: '1. birini küçümsemek, birini aşağılamak; 2. birini alaya almak; 3. yaranma gayesiyle birini yalandan övmek'. Aslında fiilin 'birini alaya almak' anlamı 'birini küçümsemek, birini aşağılamak' anlamından ortaya çıkmıştır, zira alay etme'nin ilk aşaması ve kaynağı aslında 'birini küçümsemek' davranışıdır. Budizm'de 10 günahtan biri olmasının nedeninin altında yatan ana neden de 'biriyle dalga geçmek değil', 'birini küçümsemek' olmalıdır. Bu anlamda asgançu'nun asıl anlamını 'küçümseme, aşağılama' olarak düşünmek belki daha doğru olacaktır.

Eski Uygurcada *agza- yoktur, ama ondan türetilen agzan- 'ezberden okumak, söylemek' (Clauson 1972: 98b; Röhrborn 2010: 31; Nasilov et al. 2016: 26b) fiili birkaç yerde geçmektedir. Bu fiil bugünkü bazı Türk dillerinde hayatını sürdürmüştür: Hakasça axsan- (< axsa-n < agza-n < *agız+a-n) '1. söylemek, anlatmak; 2. niyazda bulunmak' (Baskakov-Inkijekova-Grekul 1953: 35b; Subrakova 2006: 88b); Kırgizca ōzan- (< ōz+a-n-< agız+a-n-) ‘söylemek, demek' (Yudahin 1985/II: 74a); Türkmence agza- (< agız+a-) 'anmak, sözünü etmek' (Kyýasowa et al. 2016: 43a).

Eski Türkçedeki agzan- (< agız+a-n-) 'ezberden okumak, söylemek' yukarıda bahsedilen seslik evrelerin ardından asga- ve asgan- fillerine dönüşmüş ve bu dönüşümün neticesinde yeni bir sözlükbirim hâline gelmiştir. Bu sözlükbirim Eski Uygurca dışında bazı Sibirya gurubu Türk dillerinde hayatını sürdürebilmiştir: Şorca asqay 'ironi, alay'; asqayla- 'alay etmek'; asqaylaq asqaylançıq 'alaycı, alay eden' (Radloff 1893: 542; Tannagaşeva-Akalın 1995: 8); Hakasça asxay (I) 'ironi, alay'; asxaylig 'ironik, alayvarî'; asxayla- 'alay etmek' (Subrakova 2006: 84b); Kumandı Ağzı asqayçıl (< asqa-y+çıl) 'alayc1, müstehzi' (Baskakov 1972: 203b). Sibirya gurubu Türk dillerinden Hakasça, Şorca ve Tuvacada nadiren, ama Altaycada daha yaygın görülen fiilden isim yapan bir $\{-(\mathrm{I}) \mathrm{y}\}$ ekinden bahsediliyor (Kara 2005: 349-350). Krş. Hakasça çaltıray 'parılttı' < çaltıra-y < yaltıra- 'parıldamak'; tolgay 'dolambaçlı' < tolga-y < tolga- 'dolamak', vs. Buna göre Hakasça ve Şorcada Eski Türkçedeki *agza-'nın göçüşmeli şeklinin yaşadığı anlaş1lıyor: *agza> *azga- > *asga- > asqa- asxa-. Yakutça ve Dolgancada da kelimenin türemeleri görülür. Yakutça askay 'alay'; raskaydā- 'alay etmek'; ıaskaydāx 'alayvarî' (Pekarskim 1927: 3751; Sleptsova 2017: 341b-342a). Dolganca ıahaqtā- '1. şaka yapmak; 2. 


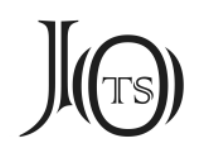

meşgul etmek'; ıahaq 'şaka'; ıahaqtāq 'şaka, espri'; ıahaqçıt 'şakacı'; ıahaqtahī 'şakac1'; ıahaqtan- '1. eğlenmek; 2. bir şeyle meşgul olmak'; ıahaqtas- 'şakalaşmak' (Stachowski 1993a: 257; 1998: 275-276).

Bu arada, Şorca askay 'şaka', Yakutça ıaskay (sic!) 'şaka' ve Hakasça askayla'alay etmek' kelimelerinin kaynağını agız 'ağız' ile ilgili olabileceğini ilk ve tek fark eden kişi yanılmıyorsam RÄsÄNEN olmuştur (1969: 29a), ancak o bunların yapısını açıklayamamıştır.

Burada agız isim kökünden türetilen agazlan- < agız+lan- fiil gövdesinden de kısaca bahsetmek istiyorum. Aslında şimdiye kadar sadece Manici çevreye ait bir metin olan MIK III 198 numaralı parçada tanıklanmıştır. RöHRBORN, sözlüğünün eski versiyonunda fiili agazlanmış 'aktarılmış (?)' (1977: 62b) şeklinde okuyup çevirmiştir. CLAUson, sözlüğünde Kaşgarî̀ye dayanarak agızla- '1. kanal için ağız açmak; 2. ağza vurmak' ve MIK III 198 numaralı parçaya dayanarak da agızlan- 'ezberden okumak' tanıklarını zikretmiş ve ikincisinin Kaşgarî’nin kaydettiği agızlafiilinden geldiğini ifade etmiştir (1972: 98b). ERDAL, fiili agızlan- 'ezberden okumak' şeklinde okur, ama Kaşgarî̀nin kaydettiği agızla- ile bu fiilin bir ilgisinin olmadığını belirtir (1991: 510). ÖZERTURAL, MIK III 198 numaralı parçadaki fiili agazlan- şekilde okumuş, ama fiile 'başlanmak' anlamını vermiştir, zira ona göre agazlan- Soğdça " $\gamma$ 'z [āyāz] 'baş, başlangıç' ismine dayanmaktadır (2008: 145-146). RöHRBORN, sözlüğünün yeni versiyonunda agazlan-'in ya Türkçe agızlan-'a (< agız+la-n-) ya da Soğdça a $\bar{\gamma} \bar{a} z+\{+1 A n-\}$ 'a dayandığını söylemiş, buna bağlı olarak fiilin metinde 'nakledilmek, aktarılmak' veya 'başlanmak' anlamında olabileceğini ifade etmiştir (2010: 21). CLARK, MIK III 198 numaralı parçanın yeni neşrinde tanığı ag(i)zlan- olarak okur ve fiili 'ezberden okumak' anlamında düşünür. Ayrıca, metindeki agızlan- tanığının Kaşgarî’nin kaydettiği agızla- tanığından ayrılması gerektiğini söylemiştir (2017: 73).

MIK III 198 numaralı parçada agazlan-'in geçtiği cümleye tekrar bakalım: yme ulug élig azruwā tenri atına yme agazlanmış boltı [ulu]g ögrünçün yme bitilm[iş] boltı agır sevinçin (T II D 171 v1-5). Bence ÖZERTURAL'in ve RÖHRBORN'un anlamlandırması ve köken önerisi doğru olamaz. Burada fiil 'ezberden veya irticalen söylemek, konuşmak' anlamında olmalıdır. Metnin bağlamından anlaşıl- 


\section{$J(\Theta)$}

dığ kadarıyla önce 'konuşma' eylemi, daha sonra 'yazma' eylemi gerçekleşmektedir. Buna göre metindeki cümlenin şöyle aktarılabileceğini düşünüyorum: "Ve [kitap] yüce hükümdar Azruwā adına (hürmetine ?) büyük coşkuyla söylenmiş ve büyük sevinçle yazılmış oldu".

Kelimenin Soğdça kökenli olduğu görüşe gelince, Soğdça " $\gamma^{\prime} z$ [āyāz] 'baş, başlangıç' ismine hiçbir Uygurca metinde rastlanmaz, yani Eski Uygurcaya bu Soğdça isim kökü görebildiğim kadarıyla hiçbir zaman ödünçlenmemiştir. Bu nedenle agazlan-'in isim kökünün Soğdça düşünülmesi için bir neden yoktur. Diğer taraftan, ÖZERTURAL'ın yeniden neşrettiği metinde 'ağız' anlamındaki söz agaz olarak geçmektedir (T II D 171 r7). Maniheist çevreye ait Uygur harfli metinlerde /1g/ veya /g1/ hecesine sahip sözlerdeki /1/'ların elif ile yazıldığı biliniyor (Erdal 2004: 43-44, 61). Dolayısıyla metindeki agaz'ın Eski Türkçe metinlerdeki standart agız ile aynı olduğu düşünülebilir. Eski Türkçe agızla- ve agızlan- fiili Hakasçada çeşitli anlamlarda yaşamaktadır: āsta- 'dedikodu yapmak' (Baskakov-Inkijekova-Grekul 1953: 12a; Subrakova 2006: 20a); āstan- '1. küfretmek, kaba konuşmak; 2. kendisinden bahsetmek' (Baskakov-InkijekovaGrekul 1953: 12a). Anadolu ağızlarında agızla- 'birine bir iş başlamak vs.' (ayrıca agızlaş-, agızlat-, vs.) (DS: 97a-98a) anlamında kullanılmaktadır. Anadolu ağızlarındaki bu tanığın anlamına bakıldığında kökün Soğdça " $\gamma^{\prime} z$ [āyāz] 'baş, başlangıç' olabileceği zannına kapılabilir, ancak Anadolu ağızlarında agız'ın bir türemesi bu ihtimali çürütür. Krş. ağızlık ‘bir şeyin başladığı yer' (DS: 98b).

Ancak Farsça āgāz 'başlangıç’ sözünün Orta Türkçe kaynaklarda, Osmanlı ve Çağatay sahası klasik şiir metinlerinde ${ }^{7}$ Türkçe yardımcı fiil ile beraber kullanımına rastlanıyor: āgāz eyle- 'başlamak'; āgāz ét- 'başlamak'; āgāz kıl- ‘söze, konuşmaya başlamak'; āgāz ol- 'başlanmak'. Orta Türkçe döneminde agazlan- fiili 'ağzına koymak, ağızda tutmak' anlamındadır: Kim Hızır suyın agızlangay lebinnin qaşıda // Kim Mesih elfāẓıdın dégey kelāmıı barıda (Babür Divanı, Yücel 1995: 53); Pisteler agızlanırmış leblerüy cüllābını // Söylenürmiş goncalar gülberg i handān haqqina (Necati Bey Divanı, Yılmaz 2015: 489 [396]).

Tanıklar için internetteki "www.tebdiz.com" projesinden faydalanılmıştır. 


\section{$J(\Theta)$}

Sonuç olarak, Eski Uygurca asgançu'nun kökeninin Türkçe içinde aranabileceğini ve kelimenin şöyle tahlil edilebileceğine inanıyorum: *agız+a- > *agız+a-nçu > *agzançu > *azgançu > asgançu. Budizm'de 10 günah içinde yer alan ve dil ile gerçekleştirilen 4 günahtan biri olan asgançu ve asgançula-'nın agız ile ilgili olması şaşırtıcı değildir. Bu anlamda asgançu'nun '1. küçümseme, aşağılama; 2. alay' ve asgançula-'nın ise '1. birini küçümsemek, birini aşağılamak; 2. birini alaya almak; 3. yaranma gayesiyle birini yalandan övmek' anlamında olabileceği düşünülebilir. Eski Uygurcada asgançu'nun türetilişinde Soğdça sx'nt 'alay etmek' veya Partça 'sxnd 'alay etmek' kelimelerinin analojik tesirinin olabileceği de hesaba katılabilir. Makalede önerilen köken teklifi kabul edilecek olunursa, iki kelimenin asqançu ve asqançula-ile değil, asgançu ve asgançula- şeklinde okunması doğru olacaktır.

\section{Kisaltmalar}

AY = Altun Yaruk'un St. Petersburg yazmas1.

bk. = Bakınız.

DKPAM = Daśakarmapathāvadānamālā.

DS = Türkiye'de Halk Ağzından Derleme Sözlüğü (1993).

krş. = Karşılaştırınız.

$\mathrm{r}=$ recto (ön).

$\mathrm{v}=\mathrm{verso}($ arka).

\section{Kaynakça}

ARAT, R. R. (1942). “Uygurlarda Istılahlara Dair”, Türkiyat Mecmuas1, 7-8/1: 56-81.

BAILEY, H. W. (1979). Dictionary of Khotan Saka, Cambridge-New York: Cambridge University Press.

BANG, W. \& A. von GABAIN (1930a). Türkische Turfan-Texte IV, ein neues uigurisches Sündenbekenntnis, Berlin (SPAW. Phil.-hist. Kl. 1930/24: 432-450).

BANG, W. \& A. von Gabain (1930b). "Uigurische Studien, 1. Das Sündenbekenntnis aus dem Suvarṇaprabhāsa”, Ungarische Jahrbücher, 10: 193-210. 


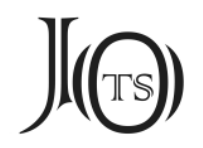

BANG, W. (1925). “Turkologische Briefe aus dem Berliner Ungarischen Institut, Dritter Brief: Vorläufiges über die Herkunft des türk. Ablativs”, Ungarische Jahrbücher, 5: $392-410$.

BANG, W. (1926). "Türkische Bruchstücke einer nestorianischen Georgspassion”, Le Muséon, 39: 41-75.

BANG, W. (1931). “Manichäische Erzähler”, Le Muséon, 44: 1-36.

BARAT, K. (2000). Xuanzang, the Uygur-Turkic Biography of the Seventh-Century Chinese Buddhist Pilgrim, Ninth and Tenth Chapters, Bloomington-Indiana: Indiana University Research Institure for Inner Asian Studies.

BASKAKOV, N. A \& A. I. InKIJEKOVA-GREKUl (1953). Hakassko-Ruskiy Slovar' (okolo 14000 slov), Moskva: Gosudarstvennoye Izdatel'stvo Inostrannıx i Natsional'nıx Slovarey.

BASKAKOV, N. A. (1972). Dialekt Kumandintsev (Kumand1-Kici), Grammatiçeskiy Oçerk, Tekstı, Perevodı i Slovar', Moskva: Izdatel'stvo "Nauka”.

CLARK, L. (2017). Uygur Manichaean Texts III: Ecclesiastical Texts, Texts, Translations, Commentary, Turnhout (Belgium): Brepols Publishers.

Clauson, Sir G. (1972). An Etymological Dictionary of Pre-Thirteenth Century Turkish, Oxford: Oxford University Press.

DURKIN-MEISTERERNST, D. (2004). Dictionary of Manichaean Texts III/1: Texts from Central Asia and China (Texts in Middle Persian and Parthian), Turnhout (Belgium): Brepols Publishers.

ERDAL, M. (1991). Old Turkic Word Formation, a Functional Approach to the Lexicon I-II, Wiesbaden: Harrassowitz Verlag.

ERDAL, M. (2004). A Grammar of Old Turkic, Leiden-Boston: Brill.

GENG, Sh. et al. (1998). Eine Buddhistische Apokalypse: die Höllenkapitel (20-25) und die Schlußkapitel (26-27) der Hami-Handschrift der alttürkischen Maitrisimit, unter Einbeziehung von Manuskriptteilen des Textes aus Säyim und Murtuk, Wiesbaden: VS Verlag für Sozialwissenschaften.

GILES, A. H. (1964). A Chinese-English Dictionary I-II, Second Edition (Revised \& Enlarged. Shanghai-London 1912, Shanghai-London: Kelly and Walsh), Taipei: Literature House. 


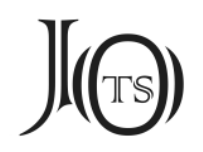

HIRAKAWA, A. (1997). A Buddhist Chinese-Sanskrit Dictionary, Tokyo: The Reiyuka.

KARA, M. (2005). Hakas Türkçesinde İsim, Gazi Üniversitesi, Sosyal Bilimler Enstitüsü, Türk Dili ve Edebiyatı Anabilim Dalı, Ankara. (Yayımlanmamış Doktora Tezi)

KASAI, Y. (2011). Der alttürkische Kommentar zum Vimalakīrtinirdeśa-Sūtra, Berliner Turfantexte 29, Turnhout (Belgium): Brepols Publishers.

KaYA, C. (1994). Uygurca Altun Yaruk, Giriş, Metin ve Dizin, Ankara: Türk Dil Kurumu Yayınları.

KYÝAsowA, G. et al. (2016). Türkmen Diliniň Düşündirişli Sözlügi I: A-Ž, Aşgabat: Ylym.

MAUE, D. \& K. RöHRBORN (1984). "Eine buddhistischer Katechismus in alttürkischer Sprache und tibetischer Schrift I", Zeitschrift der Deutschen Morgenländischen Gesellschaft, 134/2: 286-313.

MAUE, D. \& K. RöHRBORN (1985). "Eine buddhistischer Katechismus in alttürkischer Sprache und tibetischer Schrift II", Zeitschrift der Deutschen Morgenländischen Gesellschaft, 135/1: 68-91.

MÜLLER, F. W. K. (1908). Uigurica [I], 1. Die Anbetung der Magier, ein christliches Bruchstück. 2. Die Reste des buddhistischen „Goldglanz-Sūutra“, ein vorläufiger Bericht, Berlin. (AKPAW. Phil.-hist. Cl. 1908/2).

MÜLLER, F. W. K. (1911). Uigurica II, Berlin (AKPAW. Phil.-hist. Cl. 1910/3).

NADELYAYEV, V. M. et al. (1969). Drevnetyurkskiy Slovar', Leningrad: İzdatel'stvo "Nauka" Leningradskoye Otdeleniye Leningrad.

NASiLov, D. M. et al. (2016). Drevnetyurkskiy Slovar', Astana: “Gllım” Paspası.

ÖZERTURAL, Z. (2020). Uigurisches Wörterbuch, Sprachmaterial der vorislamischen türkischen Texte aus Zentralasien I/2: edäd- - iztä-, unter mit Mitwirkung von K. RöHRBORN, Stuttgart: Franz Steiner Verlag.

ÖZERTURAL, Z. (2008). Der uigurische Manichäismus: Neubearbeitung von Texten aus Manichaica I und III von Albert von Le Coq, Wiesbaden: Harrassowitz Verlag.

PeKARSKim, E. K. (1927). Slovar' Yakutskogo Yazıka III, Leningrad.

RACHMETi, G. R. (1932). Zur Heilkunde der Uiguren II, Berlin (SPAW. Phil.-hist. Kl. 1932/22: 401-448). 


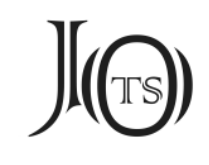

RAdloff, W. (1893). Versuch eines Wörterbuches der Türk-Dialecte I, St. Petersburg: Tipografiya İmperatorskoy Akademii Nauk.

RÄSÄNEN, M. (1969). Versuch eines etymologischen Wörterbuchs der Türksprachen, Helsinki: Suomalais-Ugrilainen Seura.

RÖHRBORN, K. (1988). Uigurisches Wörterbuch, Sprachmaterial der vorislamischen türkischen Texte aus Zentralasien 4: asankelıg-ayat-, Wiesbaden: Franz Steiner Verlag.

RÖHRBORN, K. (1977). Uigurisches Wörterbuch, Sprachmaterial der vorislamischen türkischen Texte aus Zentralasien 1: a-agrig, Wiesbaden: Franz Steiner Verlag.

RÖHRBORN, K. (2010). Uigurisches Wörterbuch, Sprachmaterial der vorislamischen türkischen Texte aus Zentralasien I/1: ab- äzüglä-, Stuttgart: Franz Steiner Verlag.

RöHRBORN, K. (2015a). Uigurisches Wörterbuch, Sprachmaterial der vorislamischen türkischen Texte aus Zentralasie II/1: a-asvık, Stuttgart: Franz Steiner Verlag.

RÖHRBORN, K. (2015b). “Kollektaneen zum Uigurischen Wörterbuch: Die dritte Wortsünde erig sarsıg sav", Kutadgu Nom Bitig, Festschrift für Jens Peter Laut zum 60. Geburtstag, Hrsg. von E. Ragagnin \& J. Wilkens, Harrassowitz Verlag, Wiesbaden: 471476.

Sims-Williams, N. \& D. Durkin-Meisterernst (2012). Dictionary of Manichaean Sogdian and Bactrian, Brepol: Turnhout (Belgien).

SLEPTSOVA, P. A. (2017). Bolşoy Tolkovıy Slovar’ Yakutskogo Yazıka XIV (Ч-Ы), Novosibirsk: Nauka.

Soothill, W. E. \& L. Hodous (1937). A Dictionary of Chinese Buddhist Terms with Sanskrit and English Equivalents and a Sanskrit-Pali Index, London: Kegan Paul, Trench, Trübner \& Co.

STACHOWSKI, M. (1993a). Dolganischer Wortschatz, Kraków: Nakładem Uniwersytetu Jagiellońskiego.

STAcHowsKi, M. (1993b). Geschichte des jakutischen Vokalismus, Kraków: Nakładem Uniwersytetu Jagiellońskiego.

STACHOWSKI, M. (1998). Dolganischer Wortschatz Supplementband, Kraków: Księgarnia Akademicka.

SubraKova, O. V. (2006). Hakassko-Russkiy Slovar' (Okolo 22 tis. Slov), Novosibirsk: Nauka. 


\section{J(৫)}

TANNAGAŞEVA, N. N. K. \& Ş. H. AKALIN (1995). Şor Sözlüğü, Adana: Çukurova Üniversitesi Basımevi.

TEKIN, Ş. (1980). Maitrisimit Nom Bitig, die uigurische Übersetzung eines Werkes der buddhistischen Vaibhāṣika-Schule, 1. Transliteration, Übersetzung, Anmerkungen, Berliner Turfantexte 9, Berlin: Akademie Verlag.

TiEtZe, A. (2016). Tarihî ve Etimolojik Türkiye Türkçesi Lügati (C-E) II, Ed. S. TEZCAN, Ankara: Türkiye Bilimler Akademisi Yayınları.

Türkiye'de Halk Ağzından Derleme Sözlüğü (1993). 12 Cilt, II. Bask1, Ankara: Türk Dil Kurumu Yayınları.

UÇAR, E. (2017). “Notizen zur Etymologie des alttürkischen özäl- «sich quälen»”, Central Asiatic Journal, 60/1: 1-11.

UÇAR, E. (2020). “Türkiye'deki Eski Uygurca Metin Neşirleri İçin Kullanılacak Harfçevrim ve Yazıçevrim Kılavuzu”, Journal of Old Turkic Studies, 4/1: 231-250.

WiLKENS, J. (2016). Buddhistische Erzählungen aus dem alten Zentralasien, Edition der altuigurischen Daśakarmapathāvadānamālā I-II-III, Berliner Turfantexte 37, Turnhout (Belgium): Brepols Publishers.

Yılmaz, O. (2015). Necati Bey Divanı, Metin-Tıpkıbasım, Ankara: Atatürk Kültür Merkezi Yayınları.

YudAHIN, K. K. (1985). Kirgizsko-Russkij Slovar' I-II, Frunze: Glavnayja Redaktsija Kirgizskoj Sovyetskoj Entsiklopedii.

YÜCEL, B. (1995). Bâbür Dîvânı (Gramer-Metin-Sözlük-Tıpkıbasım), Ankara: Atatürk Kültür Merkezi Yayınları.

ZIEME, P. (1985). Buddhistische Stabreimdichtungen der Uiguren, Berliner Turfantexte 13, Berlin: Akademie Verlag.

Zieme, P. (2015). Altuigurische Texte der Kirche des Ostens aus Zentralasien, Piscataway, NJ: Gorgias Press. 